\title{
SISTEM INFORMASI PENJADWALAN OTOMATIS MEDIA SOSIAL INSTAGRAM UNTUK MENDUKUNG PROMOSI PROGRAM STUDI DI UNIVERSITAS DHARMA ANDALAS
}

\author{
(Faradika, S.Kom, M.Kom, Renita Astri,S.Kom, M.Sc, Zulfahmi, S.Kom, M.Kom) \\ Universitas Dharma Andalas, Jl. Raya Masjid Akbar-Jati-Padang Timur \\ email: penulis Faradika@unidha.ac.id \\ Universitas Dharma Andalas, Simp By Pass No 8 Padang \\ email: rethakamal@unidha.ac.id \\ Universitas Dharma Andalas, Komp Alam Indah Lubuk Minturun B-5 Padang \\ Email: da.syam@unidha.com
}

\begin{abstract}
Instagram's social media automatic scheduling system is one of the innovations in the field of promotion to introduce study programs to many people through social media. With this scheduling application, it will be easy for the university to schedule content to be published on Instagram social media. This application works on the desktop made with the PHP programming language with MySQL database support. This research was conducted to obtain data directly from the Social Media Manager of the Study Program by conducting observations and direct interviews to the management team and related parties so that the data contained in this report is real. The system testing that is carried out is how the application works as a whole, namely where the system can send scheduling automatically to Instagram which is contained in the database, there is an input update from a user (in this case a lecturer user) through the existing application.
\end{abstract}

Keywords: Social Media, Promotion, Instagram

\section{PENDAHULUAN}

Dalam dunia pendidikan saat ini peneyelenggara pendidikan seperti Program Studi harus terlibar langsung untuk memberikan informasi tentang Program Studinya kepada Calon mahasiswa baru, baik berupa penyampaian visi dan misi, serta memberikan informasi lengkap kepada calon mahasiswanya, sehingga program studi saat ini bersaing untuk mendapatkan mahasiswa unggulan, terutama bagi kampus swasta, karena kepercayaan masyarakat kepada sebuah Universitas adalah tanggungjawab program studi yang berhubungan langsung dengan mahasiswa.

Salah satu hal yang dilakukan oleh program studi adalah dengan menjadikan media sosial sebagai sarana mendekatan kmonunikasi dengan mahasiswa dan calon mahasiswa. Menggunakan Media Sosial Instagram adalah salah satu yang efektif saat ini, Indonesia dengan angka pengguna Instagram terbanyak e 4 di dunia, kampus dan program studi berusaha menemukan calon mahasiswa baru di Media sosial ini.

Untuk mendapatkan perhatian lebih di media sosial Instagram, tentu program studi harus memiliki sebuah akun Instagram yang mampu menarik perhatian calon mahasiswa secara alami, salah satu caranya adalah dengan memberikan konten yang tepat dan up to date, seiring dengan itu, program studi di UNIDHA memiliki permasalahan utama dalam mengelola akun Instagram adalah kurangnya konten dan tidak konsistennya update dari Instagram program studi, sehingga akun Instagram tersebut seperti tiak diurus dan dikelola dengan baik, sehingga berdampak buruh 
terhadap penilaian calon mahasiswa baru UNIDHA.

Melihat permasalahan seperti diatas, peneliti merancang sebuah "Sistem Informasi Penjadwalan Otomatis Media Sosial Instagram untuk Mendukung Promosi”.

Berdasarkan latar belakang masalah, penulis merumuskan masalah yang muncul sebagai berikut

1. Bagaimana proses pengelolaan Postingan terjadwal di media sosial Instagram

2. Bagaimana solusi untuk mengatasi masalah tidak up to datenya media sosial

3. Bagaimana meningkatkan interaksi calon mahasiswa baru dengan program studi

Tujuan dari penelitian ini adalah antara lain:

1. Untuk mengetahui serta memahami sampai sejauh mana pengembangan sistem informasi yang digunakan pada proses pengelolaan moedia sosial

2. Merancang suatu sistem pengolahan jadwal otomatis posting di media sosial instagram

3. Meningkatkan Konsistensi Program Studi dalam Melakukan update Media sosial

\section{METODE PENELITIAN}

Untuk mencapai keakuratan dan ketelitian data serta informasi dalam penelitian ini, maka pengumpulan data di lakukan dengan 3 cara :

\section{Penelitian lapangan (Field Research)}

Penelitian ini dilakukan untuk mendapatkan data secara langsung dari Pengelola Media Sosial Program Studi dengan melakukan Observasi dan wawancara langsung ke tim pengelola serta pada pihak - pihak yang terkait sehingga data yang dimuat dalam laporan ini nyata kebenarannya.

\section{Penelitian Perpustakaan (Library Research)}

Penelitian ini dilakukan dengan membaca buku - buku literature, yang di jadikan sebagai bahan.

\section{Penelitian Laboratorium (Laboratory Research)}

Penelitian yang didukung perangkat komputer sebagai alat bantu dalam percobaan penyelesaian masalah. Data yang akan digunakan dalam penyusunan sistem informasi berbasis komputer harus diolah dengan program aplikasi yang sesuai dengan kebutuhan pemakai, oleh sebab itu penerapan sistem informasi berbasiskan komputer dapat dilakukan dengan menggunakan komputer yang dibutuhkan.

4. Merancang Program aplikasi untuk membantu mengolah data yang di dapat pada saat melakukan penelitian.

5. Adapun spesifikasi hardware dan software yang di gunakan sebagai berikut :

\section{A. Hardware (perangkat keras)}

Merupakan komponen secara fisik yang dapat dilihat dan disentuh.

Spesifikasi Hardware yang dibutuhkan adalah :

1. Processor intel core i3

2. Flash Disk 4 GB

3. Printer cannon Epson IP1110 
4. Memory 2 GB DDR3 dan 320 GB HDD

5. Mouse : Optic Lexron

6. Monitor

7. Laptop

B. Software (perangkat lunak)

1. Sistem Operasi Windows 7

2. Microsoft Office 2007 dan microsoft visio

3. Nexpost

4. Serta Software pendukung lainnya.

\section{HASIL DAN PEMBAHASAN}

Pengujian sistem yang dilakukan adalah cara kerja aplikasi secara keseluruhan, yaitu dimana sistem dapat mengirimkan penjadwalan secara otomotis pada Instagram yang terdapat dalam database, adanya masukan update dari seorang user ( dalam hal ini user dosen ) melalui aplikasi yang ada.

\section{A. Aliran Sistem Informasi Baru}

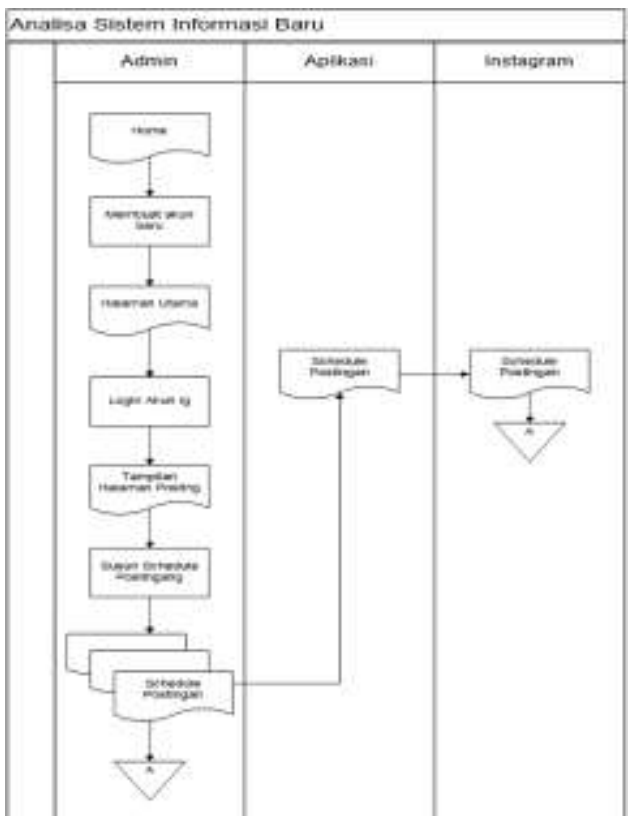

Gambar.1 Aliran sistem informasi baru

Pada gambar diatas adapun aktifitas aliran sistem informasi inventaris aset tetap yang sedang berjalan adalah :

Admin membuka tampilan Home dan membuat akun baru, kemudian admin melakukan login pada akun Instagram danmenyusun schedule postingan yang akan di posting dan akan langsung terkoneksi ke aplikasi dan akun Instagram.

B. Use Case Diagram

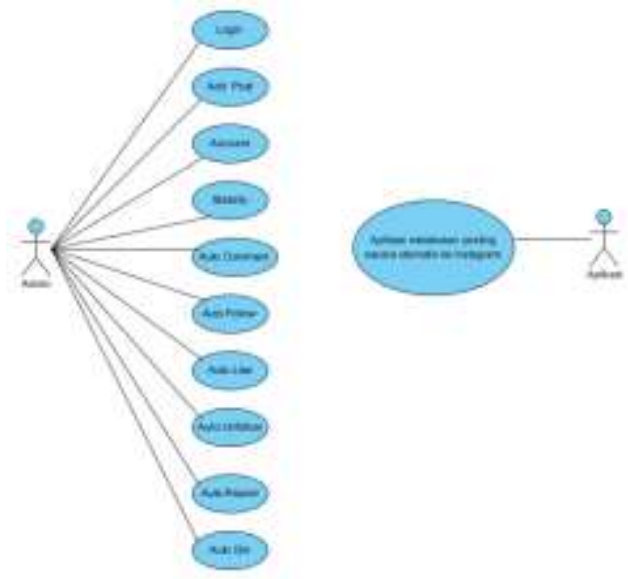

Gambar.2 use case diagram

Pada Gambar diatas adapun aktifiats aliran sistem informasi inventaris asset tetap yang sedang berjalan adalah

1. Admin hanya bisa melakukan login pada halaman utama, adapun sistem yang bisa dilakukan oleh admin adalah add post, accound, statistic, auto coment, auto follow, auto like, auto unfollow, auto repost, dan auto dm.

2. Aplikasi hanya bisa melakukan posting secara otomatis pada Instagram

C. Sequence Diagram 


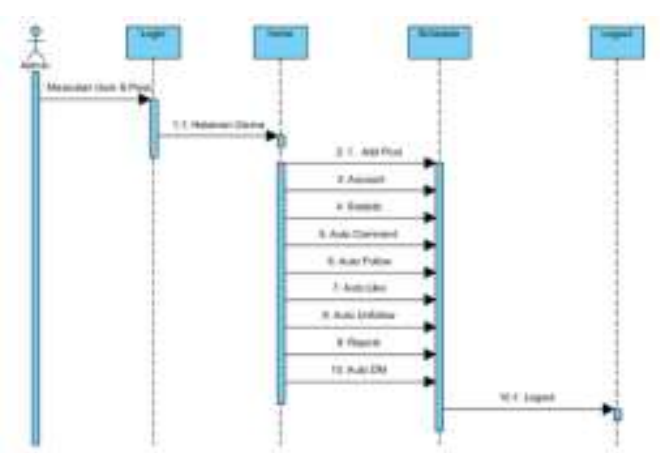

Gambar.3 Sequence Diagram

Pada Gambar diatas adapun aktifiats aliran sistem informasi inventaris asset tetap yang sedang berjalan adalah

1. Kepala bagian umum memasukan username dan password agar masuk ke sistem

2. setelah masuk ke sistem admin bisa melihat tampilan home dan melihat halaman menu utama

3. setelah itu admin bisa melakukan add post, account, statistic, auto follow, auto like, auto unfollow, auto repost dan auto DM

4. setelah itu admin keluar dari sistem

D. Aktivity Diagram

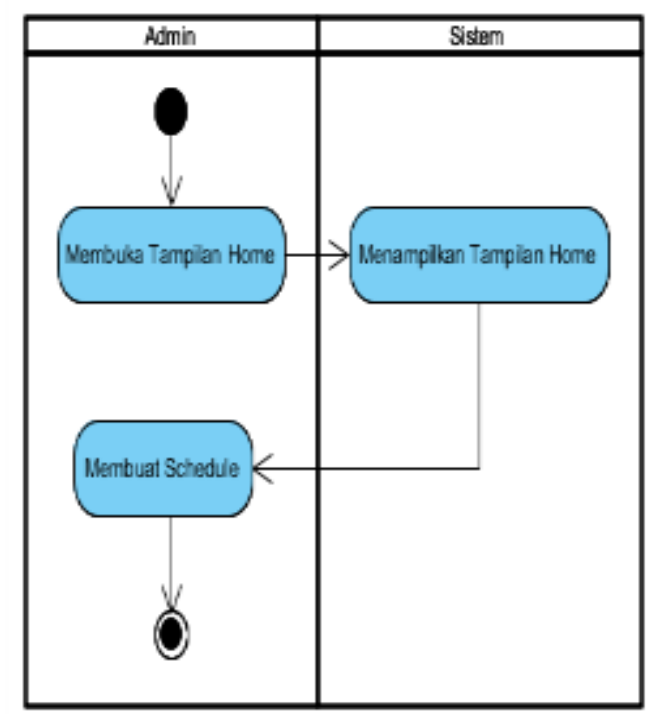

Gambar.4 Aktivity Diagram

Penjelasan pada gambar di atas adalah

Admin membuka tampilan home dan sistem menampilkan tampilan home kemudia admin membuat schedule postingan.

\section{HASIL PROGRAM}

1. Halaman Registrasi dan Masuk

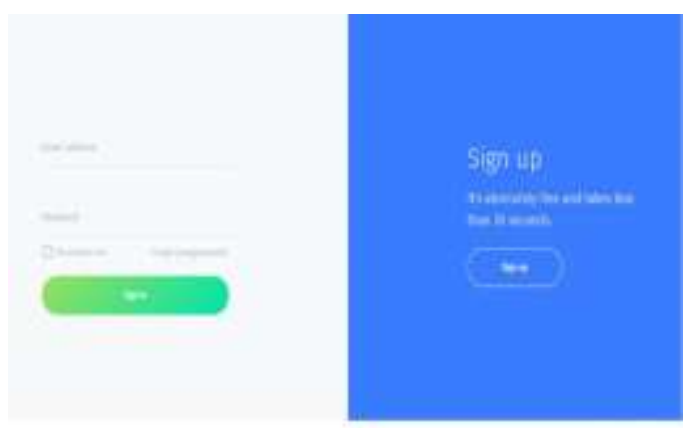

Gambar.1 Tampilan halaman Regitrasi dan Halaman Login aplikasi Penjadwalan otomatis

2. Beranda Aplikasi

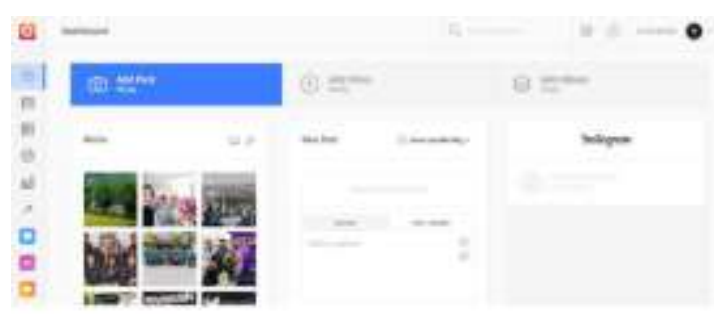

Gambar 2. Halaman Beranda Aplikasi Penjadwalan Otomatis

3. Halaman Tambah Akun Instagram 


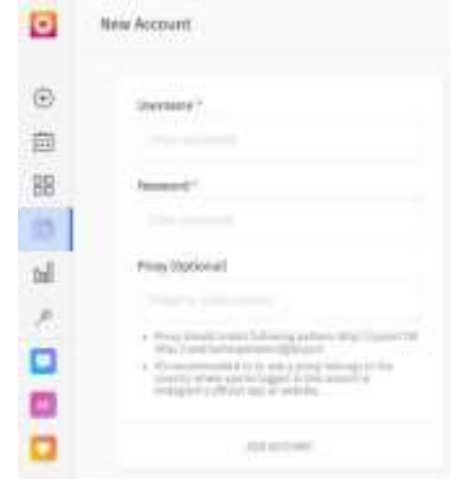

Gambar 3. Tampilan Penambahan Akun Instagram

4. Tampilan halaman Penjadwalan Otomatis

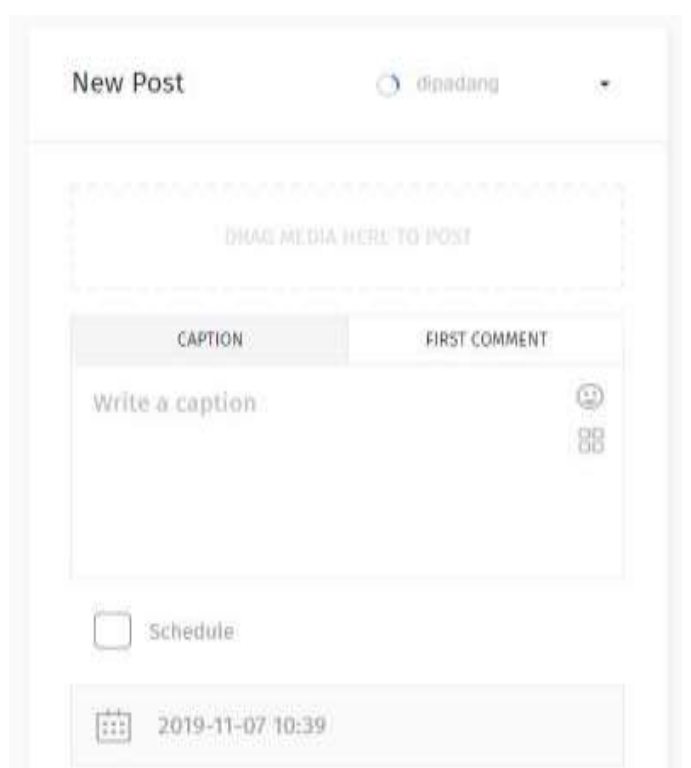

Gambar 4. Halaman Penjadwalan Otomatis Posting ke Instagram

\section{SIMPULAN}

Berdasarkan hasil pembahasan tentang Sistem Informasi Penjadwalan Otomatis Media Sosial Instagram untuk Mendukung Promosi yang telah di uraikan adalah dengan adanya sistem informasi ini dapat dengan mudah menyusun jadwal kuliah yang Sudah di tetapkan tanpa adanya perulangan mata kuliah yang sama pada sistem.

Penulis dapat memberikan saran terhadap pengguna sistem informasi yang di buat adalah

1. Sistem Informasi yang telah diimplementasikan harap dilakukan perawatan berkala (Maintenance), karena untuk menghindari adanya aplikasi yang crash secara tiba tiba, entah pada saat pengoperasian penjadwalan maupun penyimpanan dalam database.

2. Sistem Informasi inventaris ini diharapkan adanya pengembangan lebih lanjut guna membantu permasalahan - permasalahan pembaruan jadwal yang akan di posting

\section{UCAPAN TERIMAKASIH}

Alhamdulillah, berkat rahmat Allah SWT yang telah memberikan segala karunia-Nya sehingga penulis dapat menyusun laporan penelitian ini dengan baik dan tepat waktu. Dan tak lupa shalawat dan salam kepada Nabi Besar Muhammad SAW yang telah berjasa besar dengan membukakan jalan dalam perkembangan ilmu pengetahuan seperti sekarang ini.

Tujuan dari penelitian ini adalah untuk membantu Program Studi di Universitas Dharma Andalas dalam mengelola Media Sosial Instagram, diharapkan para Program Studi dapat meningkatkan promosi dengan tepat dan bisa meningkatkan jumlah mahasiswa.

Hasil Penelitian ini nantinya juga diharapkan dapat memperkaya khasanah ilmu pengetahuan terutama di bidang teknologi informasi serta dapat dijadikan sebagai referensi untuk penelitian selanjutnya . Atas dukungan dan dorongan semua pihak dalam penulisan proposal ini 
penulis mengucapan terima kasih yang sebesar-besarnya. Semoga dapat member manfaat bagi kita semua.

\section{DAFTAR PUSTAKA}

1. Anisya. 2013. “Aplikasi Sistem Database Rumah Sakit Terpusa Pada Rumah Sakit Umum(RSU)Aisyiyah Padang dengan menerapkan Open Source(PHP-MYSQL)'. Jurnal Momentum Vol. 15 No.2 Agustus 2013, ISNN 1693-752X

2. Bunafit Nugroho. 2005" Database Relasional dengan MySQL". Yogyakarta : Andi Offset.

3. Gandung Triyono. 2011.' Pertimbangan Melakukan Denormalisasi pada Model Basis Data Relasi “. Jurnal TELEMATIKA MKOM, Vol.3 No.2 September 2011, ISSN 2085$725 \mathrm{X}$.

4. HM, Jogiyanto. 2005. Analisis Dan Desain Sistem Informasi.

Yogyakarta : Andi Offset.

5. Kadir, Abdul dan Terra

CH.Triwahyuni. 2009.

Penngenalan Teknologi Informasi

. Yogyakarta : Andi offset

6. Khoirin Naskin. 2012. "Pengembangan Sistem Informasi Akademis dan Keuangan di Man 2 Pati". Jurnal on Computer Science Speed- FTI UNSA Vol.9 No.3 Desember 2013, ijcss.unsa.ac.id

7. Minarni dan susanti. 2014." Sistem Informasi Inventory Obat Pada Rumah Sakit Umum Daerah (RSUD) Padang”. Junal
Momentum vol.16 No.1 Februari 2014, ISSN 1693-752X.

8. Sri Dewi Anggadini. 2014. "Prosedur Pembayaran Gaji Pegawai dengan Sistem Apllication And Product In Data Processing (SAP) pada PT.PLN (persero)". Majalah Ilmiah UNIKOM Vol. 10 No.2 .

9. Suratman, MBM Munir, Umi Salamah. 2013" Ilmu Sosial Dan Budaya Dasar “. Malang : Mukti Brabowo.

10. Arno, S., 2018. SISTEM

INFORMASI GEOGRAFIS OBJEK WISATA KABUPATEN LIMA PULUH KOTA UNTUK MENDUKUNG PROMOSI PARIWISATA DAERAH. Jurnal Sains dan Informatika, 4(2), p.118. 11. Astri, R., \&amp; Sularno. (2020). Implementation of A-Star Algorithm for Searching Routes Near the Tsunami Evacuation Shelter Point. Jurnal RESTI (Rekayasa Sistem Dan Teknologi Informasi), 4(2), 254-259. doi:10.29207/resti.v4i2.1602 